\title{
Implications of Uncertainty Avoidance and Procrastination on Some West African EFL Learners' Academic Behaviors
}

\author{
Moussa Tankari ${ }^{1 *}$, Coffi Martinien Zounhin Toboula ${ }^{2}$, Hamissou Ousseini ${ }^{3}$ \\ ${ }^{1}$ University of Zinder (Niger) \\ ${ }^{2}$ University of Abomey-Calavi (Benin) \\ ${ }^{3}$ Abdou Moumouni University (Niger)
}

*Corresponding Authors: Moussa Tankari, University of Zinder (Niger)

\begin{abstract}
This descriptive study that focused on a quantitative approach aims at exploring the factors that promote the avoidance of uncertainty and procrastination in English as a Foreign Language (EFL) learners. Recognized as being the major problem that prevents these learners from taking online courses, it is important to find suitable solutions to this for these students' good, especially in these times of expansion of e-learning due to the advent of the COVID-19 pandemic. Through a semi-structured questionnaire of the 5-point Likert scale composed of 24 items administered to 230 learners recruited online in Benin and Niger, various quantitative data were collected, crossed, and analyzed through a descriptive interpretation statistical method of PASW 26 software. From the results obtained, it emerges that the majority of respondents (85.32\%) are subject to the phenomenon of uncertainty avoidance and procrastination and this would be caused by the lack of self-confidence, motivation, sociability, self-regulation, dedication, self-sacrifice, and anxiety management. However, it turned out that the aforementioned phenomenon is not the prerogative of a particular gender but is linked to the socio-cultural environment of each one. Among other recommendations made are the development of the notions of self-study, self-control, motivational factors, knowledge in ICT, and the adoption of a rule of life.
\end{abstract}

KEYWORDS : uncertainty, avoidance, procrastination, e-learning, EFL

\section{INTRODUCTION TO THE STUDY}

The objective of the present research work is twofold. It aims first at appreciating the factors Influencing learners' academic behaviors the most in terms of taking online EFL classes and then providing useful recommendations for improving instruction at large.

One of the goals of education, whether delivered in traditional, hybrid, or fully online format, is to prepare students to communicate in a variety of ways. In our present society, communication using digital media has become essential. Education keeps up growing in notoriety. As indicated by a study carried out by Allen and Seaman (2017), "slightly less than one-half [48.2\%] of students taking at least one distance course are taking only [online classes]" (p.21). Although the majority of these e-learning classes and programs put a particular emphasis on student commitment and participation, little is known about the other factors that can impact traditional face-to-face or online communication. Such considerations may be ascribed to the uncertainty or procrastination of the learner. Therefore, understanding them can help instructors design courses that foster the ability to acquire knowledge or develop the desire to belong to a learning environment to overcome great challenges such as school procrastination or even course dropout.

Studies on the learner engagement (Lee et al., 2019; Murray, 2018; NSSE, 2017; Cho and Cho, 2014; Burch et al., 2015; Dixon, 2015), procrastination (Nord by et al., 2017; Cork in et al., 2014; Grunchel et al., 2018; Visser et al., 2017), and collaboration are countless, but very few of them investigated the effect of uncertainty avoidance on the student feeling of belonging and community support. In this study different levels (low, medium, and high) of uncertainty avoidance were compared between male and female participants (from Benin and Niger republic) in a learning environment. The rationale was that certain cultural characteristics and procrastination behaviors might play out differently in students with distinct levels of uncertainty avoidance. Moreover, the present research study aims to fill that gap by examining the effects of uncertainty avoidance and procrastination on the sense of belonging and 
Implications of Uncertainty Avoidance and Procrastination on Some West African EFL Learners' Academic Behaviors

student academic behaviors such as degree of engagement, participation in forums, following the discussion, in accomplishing course-related tasks.

To meet these objectives, the following research questions were elaborated:

a) What is the impact of uncertainty avoidance and procrastination on student engagement, the feeling of belonging, collaboration, and participation?

b) Do male and female students differ in their level of uncertainty avoidance and procrastination?

After reviewing the current trends in the literature on the outcomes variables, this paper has highlighted the methodology used and the results attained. A consideration of the different findings will then be provided before concluding and giving directions for future research.

\section{REVIEW OF RELATED LITERATURE}

The initial review of related literature shows that past studies are primarily focused on describing the concept of student engagement, uncertainty avoidance, and academic procrastination in general. For example, Hofstede (1980, p.45 and 2001, pp.9-11) in his different research works compared low and high uncertainty avoidance in societies and used the degree of uncertainty avoidance to distinguish between societal norms. Hofstede (1980, p. 45) defined this concept as,

the extent to which a society feels threatened by uncertain and ambiguous situations and tries to avoid these situations by providing greater career stability, establishing more formal rules, not tolerating deviant ideas and behaviors, and believing in absolute truths and the attainment of expertise (As quoted in Kirkman, Lowe, and Gibson, 2001, p.5).

Basing on this definition, the concept of uncertainty avoidance in the context of foreign language learning can be portrayed as the time when learners feel frightened by unsure and unknown learning situations and try to avoid them by choosing the best alternative immediately available to them; that of dodging or procrastination. As described by Gargari, Sabouri, and Norzad (2011, p.76), the term procrastination has to do with "a way to avoid or escape from undesirable [or giving reasons for one's inaction by claiming a given responsibility or work is a boring task and can be postponed to the future]".Asikhia (2010, p.205) defined it as "a frequent failure at doing what ought to be done to reach one's goals". He also contented this is nowadays "a common phenomenon among students particularly those preparing for their final examination and this is doing more harm to their academic achievement than good" (2010, p.205). By referring to the findings of some research-works of which the one carried out in two Nigerian Universities (Ibadan and Lagos) in West Africa by Akinsola, Tella, and Tella (2007) on some learners' academic performance in mathematics, Asikhia (2010, p.205) reported that "there is a significant correlation between academic procrastination and mathematics academic achievement". He further suggested that the act of procrastination affects negatively the performance of learners in mathematics. This can be explained by the fact that as they procrastinate by postponing the learning of their lessons or the processing of the various tasks assigned to them in mathematics, they receive bad marks in this academic subject. Under the investigation strategy adopted by Asikhia (2010) in his research work, the present research study has also attempted to examine the possible factors that could develop the avoidance of uncertainty among EFL learners from Niger and the Benin Republic and the degree to which this could incite them procrastinating about the decision of taking online English classes. It is worthwhile investigating this issue because as reported by Asikhia (2010, p.205), some of the factors that encourage procrastination among learners have to do "[...] with low self-esteem and anxiety [...]" (Beswick, Rothblum \&Mann, 1988cited byAsikhia, 2010, p.205). From the different other studies that he referred to in his work, Asikhia (2010), reported the act of procrastination "is associated with poor academic achievement" (Beck, Koons\&Migram, 2000; Tuckman, Abry \&Smith, 2000; and Popoola, 2005 quoted in Asikhia, 2010, p.205) and that most learners with low grades in class are the ones who are more prone to procrastination (Tice \&Bauneister, 1997 cited in Asikhia, 2010, p.205).

Regarding student engagement, in their seminal work on the factors contributing to this construct, Swan et al. (2000) found that three major characteristics were associated with engagement. There are"(1) frequent and quality interaction with instructors, (2) a dynamic discussion (interaction with classmates), and (3) a transparent interface (easy navigation)" (Dixson, 2015, p.3). As for academic procrastination, it is seen as the "tendency to [1] always or nearly always put off academic tasks, and [2] always or nearly always experience problematic anxiety associated with this procrastination" (Rothblum, 
Solomon, \&Murakami, 1986, p.387 quoted in Senecal, Koestner, \&Vallerand,1995, p.608). According to Steel (2007), it is "a prevalent and pernicious form of self-regulatory failure" (p.65). Similarly, experimental studies on academic procrastination advocate "[...] the notion [of] procrastination is a motivational problem that involves more than poor time management skills or trait laziness" (Senecal, Koestner, \&Vallerand, 1995, p.608). They also revealed that though there are many causes that make learners procrastinate, most of these deal with the "fear of failure" (Solomon \&Rothblum, 1984 quoted in 1995, p.608).

Considering the correlation between self-regulation and procrastination, we can simply say that the first plays a fundamental role in the learning motivation and that the second acts negatively on this motivation. As for the notion of self-regulation, it is "a process through which the student activates and maintains thoughts, feelings, and behavior necessary for achieving personal goals" (Zimmerman \&Schunk, 2011, p.103 and p.286 cited in Visser, Korthagen \&Schoonenboom,2018, n.p). In the literature, "three different phases of self-regulation are identified when a student sets himself or herself to a given learning activity" (Ibid.). Zimmerman (2002, pp.66-68) classified them as follows:

a) forethought and planning phase (processes and beliefs that occur before efforts to learn)

b) monitoring performance and motivation phase (processes that occur during behavioral implementation)

c) reflection on performance phase and self-reflection (processes that occur after each learning effort)

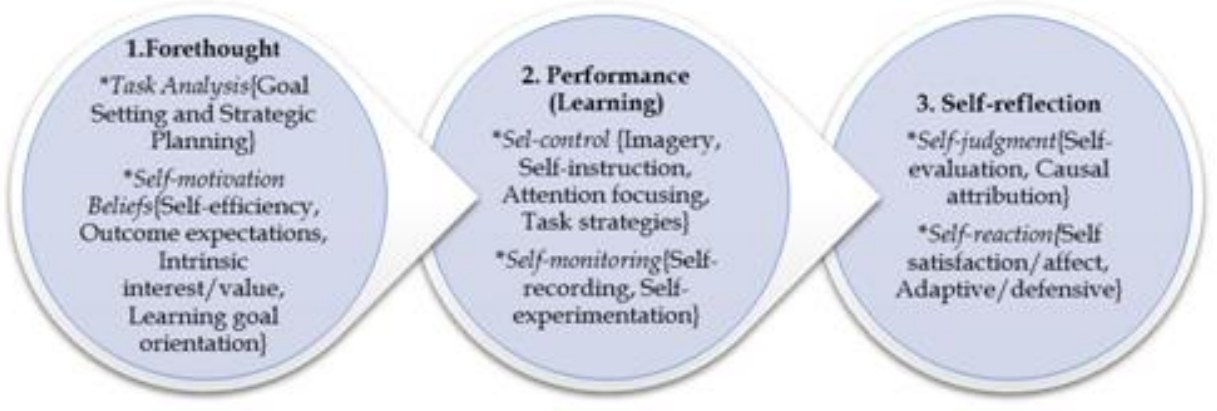

Figure1. Three Phases and Subprocesses of Self-Regulation Learning Adapted from Zimmerman (2002, p.67)

Source: Zimmerman, B. J. (2002). Becoming a self-regulated learner: An overview. Theory into Practice, 41(2), 64-70.doi:10.1207/s15430421tip4102_2[Retrieved on 09/25/2020 from https://www.researchgate.net/publication/237065878]

From the many discussions held around the issue of procrastination, it emerges that this attitude, observed especially among learners, is often interpreted differently. For many observers, this would be the result of laziness. This interpretation should therefore be examined similarly to the way Lieberman (2019) did it to explore whether everyone is prone to procrastination or not. If this should prove to be true as demonstrated by Lieberman (2019), it would then be a question of evaluating the different strategies adopted by those who are not procrastinators. It will also allow us to shed light on the different forms of procrastination that can be encountered.

While defining the word procrastination, Lieberman (2019) presented it as a unit of expression that primarily originates "from the Latin verb procrastinare [meaning] to put off until tomorrow" (n.p). However, as specified by this researcher, "it is more than just [a voluntary] delaying [or] doing something against [one's] better judgment. [As argued by Steel (2011, n.p, cited in Lieberman, 2019, n.p), procrastination is a form of] self-harm [...]" (2019, n.p). Simply put, in addition to missing out on the benefits he/she could gain in carrying out the task he/she is putting off, the procrastinator does not always realize the harm he/she is doing to himself. This suggests rationality because you cannot do something that you know pertinently being harmful to you. (Sirois \&Pychyl, 2016).

As far as the different stages of procrastination are concerned, most of the various literature (Risk, Medan, 2017, Bud, 2014, n.p) reviewed revealed that there are fundamentally five:

1. Uncertainty (Denial or refusal to recognize a situation)

2. Forethought (Intention) 
3. Productive avoidance (Abstention or non-participation, justification)

4. Distraction (Unawareness, confusion, false start)

5. Panic and regret (Stumbling, "playing things by ear", muddling through)

On a yet different note, earlier studies exploring the causes that determine students partaking in online classes found that the following points affect learners' involvement as well as the way this occurs. There are "technology and interface characteristics, content area experience, student roles and instructional tasks, and information overload" (Vonderwell \& Zachariah, 2005, p.222). What is missing from these earlier studies is a comprehensive and structured approach in assessing the effect of different levels of uncertainty avoidance on student academic behaviors and whether this difference is mitigated by gender.

\section{MeThOdOLOGY}

A survey that uses the theory of sociocultural learning as a basis is the primary research tool for this study. As specified in Wang (2007 citing the research work of late Vygotsky\&Cole, 1978), “[...] sociocultural learning theories [SCT] are learner-centered and provide insight into collaborative approaches to student learning" (p.149). In other words, this has to with what Lantolf (2004, p.30-1) identified as "[...] a theory of mind [...] that recognizes the central role that social relationships and culturally constructed artifacts play in organizing uniquely human forms of thinking' (Lantolf\&Thorne,2005, p.1-Intro).

\subsection{The SCT Theory and its Frameworks}

The theory of Sociocultural Learning (SCT) is affiliated with the famous works of Lev Vygotsky, a prominent Russian psychologist of the early $20^{\text {ieth }}$ century who passed away at the age of 37 in 1933. This scholar has advocated that a complex relationship between social groups and culture results in human growth. Moreover, he claimed that Kids learn steadily and constantly from parents and their instructors through this interplay (Lantolf, 2000, pp.198-199). As reported by Cherry (2020, n.p), Vygotsky figured this learning experience, even then, differs from one social environment to the other. It is worth bearing in mind that the theory of Vygotsky highlights this interaction's complex existence. Most of his works have shown that society not only impacts individuals but its culture is often influenced by individuals (Ibid.).

In his attempt to remedy what he considered in his time to be "the crisis of the psychological sphere" that comprised at the time different approaches including those of the natural sciences and the humanistic tradition, focused on the mental process, Vygotsky will make a significant discovery. He found that the human mind was guided more by cultural factors accepted voluntarily by the conscience than by the neurological system. Among other factors are language, literacy, rationality, logic, etc. In other words, he proved that the more apparent interaction involving individuals and the physical environment mediated by concrete natural resources can be considered in terms of understanding psychological mediation through conceptual and sociolinguistic components (Lantolf, 2000, p.199). Simply put, "physical tools allow us to change the world in ways that simple use of our bodies does not" (2000, p.199). Furthermore, "by transforming our social and material environment, we also change ourselves and the way we live in the world" (Ibid.).

There are many varieties of mediation. One of them is regulation. This can be pictured through the fact that "when children learn a language, words not only function to isolate specific objects and actions, [but] they also serve to reshape biological perception into cultural perception and concepts" (Lantolf, 2000, pp.199-200). To comment on this, we can simply state that, children acquire skills for operations (emotional and cognitive) in which their behavior is primarily managed or influenced by many others. As argued by (Lantolf, 2000, pp. 200-202), three general phases move through this process of establishing self-regulation. Kids are often regulated by or through the use of people or objects to think during the first phase. This stage is called the control of artifacts commonly known as object-regulation. This is the case of a 5-year-old kid who is asked to go and get a blue doll and comes back with a pink doll. Children are more controlled by toys at this age. Likewise, to encourage the learner to take more interest in what he/she is being taught, the teacher may use some specific materials. Two different forms of mediation (implicit and explicit) come into play during the second process, regarded as 'other- 
regulation', by allowing the learner to be encouraged by multiple educators (EFL teachers, a family member, etc.)

As for the third stage, the actual self-regulation, the one in which we are most interested in this research work, has to do with the ability to perform a task with or without minimum support from external sources. The other features of the SCT Theory as realized by Lantolf, (2000, pp. 200-204) deal with the process of "mediation through a second language" $(2000$, p.202) based on a private speech that helps to regulate the function of mental, the process of internalization and the one of imitation. Internalization is the system by which cultural objects, such as language, operate. This process, that is to say, "the essential element in the formation of higher mental functions [...]"Kozulin (1990, p. 116, cited in Lantolf, 2000, p. 203) added to that of mediation, constitutes one of the essential principles of the SCT theory. Lantolf (2000, p. 203) further clarified the notion of internalization by alluding to the idea of Winegar (1997, p. 31) who claimed," [...] this is a negotiated process that reorganizes the relationship of the individual to her or his social environment and generally carries it into future performance" (2000, p. 203). According to Vygotsky, "the key to internalization resides in the uniquely human capacity to imitate the intentional activity of other humans" (Ibid.) because, as contended by many studies such as those of Speidel and Nelson (1989 quoted in Lantolf, 2000), "imitation plays an important role in language acquisition" (2000, p. 204). Therefore, the tendency of procrastination is likely to arise if the learner is not able to internalize the notions of mental mediation and imitation by making use of the various cultural objects (such as the language) available to him/her in his/her community.

\subsection{Research Design}

A research design as defined by Burns and Grove (2003, p.195), is a model for performing research work with full control over variables that may conflict with the validity of the results. In other words, this is the various sets of preliminary decisions or plans made by the researcher while carrying out his or her study.

A quantitative research methodology has been adopted to elicit the attitudes of EFL learners about the effect of ambiguity avoidance and procrastination on their commitment, sense of belonging, cooperation, as well as involvement in English learning activities and to investigate whether this depends on gender or not. Data from some EFL students enrolled in a degree program at a higher education institution in western Niger were therefore collected for the first time in June 2020. Three months later, from a study of Beninese bachelor's degree students in the English department, the second form of data was gathered. These different data were cross-checked and analyzed through a descriptive interpretation statistical method.

\subsection{Selection of the Research Sites}

For interdisciplinary and reliability sake, the data for this study were collected from learners having in common the learning of English as a Foreign Language and who resided in two different countries, namely Benin and Niger. These different learners were recruited from the first higher educational institution in each of these two countries where the various researchers of the present study are involved as EFL instructors.

\subsection{Population}

Two different samples of intermediate learners (103 and 127) were respectively recruited from the national university of Benin and Niger republic. The distribution of the different samples of EFL learners from the two distinct geographic areas is presented in Table 1 below.

Table1. Frequency Distribution of Participants by Gender, Institution, and Marital Status

\begin{tabular}{|c|c|c|c|c|c|c|c|c|}
\hline \multicolumn{9}{|l|}{ UAC } \\
\hline & & Married & Widowed & Divorced & Separated & Single & ND & Total \\
\hline & Male & O & 0 & 0 & 0 & 63 & 8 & 71 \\
\hline \multirow[t]{2}{*}{ Gender } & Female & O & 0 & 0 & 0 & 18 & 11 & 29 \\
\hline & ND & 0 & 0 & 0 & O & 2 & 1 & 3 \\
\hline Total & & 0 & 0 & 0 & 0 & 83 & 20 & 103 \\
\hline \multicolumn{9}{|l|}{ UAM } \\
\hline & Male & 20 & 0 & 2 & 3 & 62 & 1 & 88 \\
\hline \multirow[t]{2}{*}{ Gender } & female & 22 & 0 & 0 & 0 & 16 & 0 & 38 \\
\hline & ND & 0 & 0 & 0 & 0 & 0 & 1 & 1 \\
\hline Total & & 42 & 0 & 2 & 3 & 78 & 2 & 127 \\
\hline G Total & & 42 & 0 & 2 & 3 & 161 & 22 & 230 \\
\hline
\end{tabular}


Each of the 230 participants volunteered for the study. Of the 127 EFL learners recruited in Niger, 91 were bachelor's degree students, 31 were in Master's degree studies and 05 were doctorate students. While 118 of them mentioned that they were enrolled as full-time students and 9 ( 8 males and 1 female) as non-full-time students, 8 (4 males and 4 females) of them did not disclose their enrolment status. Unlike them, most of the learners recruited in Benin mentioned that they were enrolled as full-time students in bachelor's degree studies.

\subsection{Data Collection}

To answer the two research questions, quantitative data have been collected among EFL intermediate learners from two different countries in West Africa (Niger and the Benin Republic). Given the generalized health crisis due to the COVID-19 pandemic, learners were recruited online through some groups of the social network known as "Telegram" initially created to provide online courses. There were administered semi-structured interview questions through a 5-Point Likert Scale questionnaire specially designed for the occasion. In fact, of the 353 questionnaires administered, only 230 were retrieved in all through e-mail boxes.

\subsection{Research Instruments}

Considering the global coronavirus health crisis, the only research instrument that appears at first glance to be appropriate for this pandemic concern is the questionnaire. It can help collect data from any place on earth across the internet. However, since the internet is the tool that allows the administration of questionnaires contributing then to data collection, we may also cite it as a research instrument in the context of this study.

\section{ReSUlts}

The data collected with the 5-Point Likert Scale interview questionnaire are reported below. A sample of 230 EFL learners of which100 Nigerien $(42.9 \%)$ and 5 International students $(2.1 \%)$ recruited in Niger, 103 Beninese (44.2\%) recruited in Benin, and 25 who did not mention their citizenship (10.7\%), was involved in the survey. This sample of learners was made of $159(68.2 \%)$ males and $67(28.8 \%)$. 7 of these participants (3.0\%) did not disclose their gender. Table 2 and Table 3 better illustrate this information.

\section{Table2: Frequency Distribution of Participants by Citizenship}

\begin{tabular}{llr|r|r|r}
\hline & Frequency & Percent & Valid Percent & $\begin{array}{c}\text { Cumulative } \\
\text { Percent }\end{array}$ \\
\hline \multirow{4}{*}{ Valid } & Niger & 100 & 42.9 & 48.1 & 48.1 \\
\cline { 2 - 7 } & $\begin{array}{l}\text { International } \\
\text { student }\end{array}$ & 5 & 2.1 & 2.4 & 50.5 \\
\cline { 2 - 7 } & Benin & 103 & 44.2 & 49.5 & 100.0 \\
\cline { 2 - 7 } & Total & 208 & 89.3 & 100.0 & \\
\hline Missing & System & 25 & 10.7 & & \\
\hline Total & & 233 & 100.0 & &
\end{tabular}

Table 3: Participants' Distribution by Gender

\begin{tabular}{llrrrrr}
\hline & Frequency & Percent & Valid Percent & $\begin{array}{c}\text { Cumulative } \\
\text { Percent }\end{array}$ \\
\hline \multirow{3}{*}{ Valid } & Male & 159 & 68.2 & 70.4 & 70.4 \\
\cline { 2 - 7 } & Female & 67 & 28.8 & 29.6 & 100.0 \\
\cline { 2 - 7 } & Total & 226 & 97.0 & 100.0 & \\
\hline Missing & System & 7 & 3.0 & & \\
\hline Total & & 233 & 100.0 & &
\end{tabular}


Implications of Uncertainty Avoidance and Procrastination on Some West African EFL Learners' Academic Behaviors

Table 4 helps to interpret the frequencies and percentiles values presented in Table 2 and Table 3. It shows the way the frequency of missing and percentiles were calculated by PASW 26.

\begin{tabular}{|c|c|c|c|}
\hline & & Gander Troe & Citizenghin \\
\hline \multirow{2}{*}{$\mathrm{N}$} & Valid & 226 & 208 \\
\hline & Missing & 7 & 25 \\
\hline \multirow{3}{*}{ Percentiles } & 25 & $.2 \mathrm{sh}$ & $1.04^{b}$ \\
\hline & 50 & 1.30 & 2.03 \\
\hline & 75 & 1.80 & 2.99 \\
\hline \multicolumn{4}{|c|}{$\begin{array}{l}\text { a. The lower bound of the first interval or the upper bound of the last interval is not } \\
\text { known. Some percentiles are undefined. }\end{array}$} \\
\hline \multicolumn{4}{|c|}{ b. Percentiles are calculated from grouped data. } \\
\hline
\end{tabular}

Table 5 : Bootstrap Specifications

\begin{tabular}{l|r}
\hline Sampling Method & \multicolumn{1}{|l}{ Simple } \\
\hline Number of Samples & 1000 \\
\hline Confidence Interval Level & $95.0 \%$ \\
\hline Confidence Interval Type & Percentile
\end{tabular}

The bootstrap sampling distribution estimation report performed to examine standard errors and confidence intervals for the mean, median, proportion, and correlation coefficient, variance, and standard deviation indicated that a simple method should be used. Thus, at the 5\% threshold, the confidence interval delimited by the $2.5 \%$ and $97.5 \%$ percentiles of the bootstrap distribution reveals a coefficient $\mu=95 \%$ regarding the quality of the analysis done. This suggests that the initial hypothesis that led to the use of the questionnaire as a data collection instrument is trustworthy. The sampling distribution is therefore reliable as summarized in Table 5.

\begin{tabular}{|r|r|r|}
\hline \multicolumn{3}{|c|}{ Table 6 : Reliability Statistics } \\
\hline $\begin{array}{c}\text { Cronbach's } \\
\text { Alpha }\end{array}$ & $\begin{array}{c}\text { Cronbach's Alpha Based } \\
\text { on Standardized Items }\end{array}$ & N of Items \\
\hline .684 & .688 & 24 \\
\hline
\end{tabular}

An examination of the reliability coefficient based on the value of Cronbach's Alpha the observations abovementioned and the different information illustrated in Tables 6 and7, the results suggest that the various data collected through the present study are valid and reliable.

\begin{tabular}{|c|c|c|c|}
\hline & & $\mathrm{N}$ & $\%$ \\
\hline \multirow{3}{*}{ Cases } & Valid & 212 & 91.0 \\
\hline & Excluded $^{a}$ & 21 & 9.0 \\
\hline & Total & 233 & 100.0 \\
\hline
\end{tabular}

Thus, by computing the various data through the Predictive Analytics Software (PASW) 26, formerly known as SPSS 26, the reliability coefficient obtained after the processing of cases is estimated at a value $\beta=91.0 \%$ that is very significant. Similarly, Cronbach's Alpha Based on Standardized Items has shown a value of .68that ranges from 0 to 1.00 . This reveals a greater level of internal consistency of the 5-point scale questionnaire made of 24 items that have been administered to the learners.

\begin{tabular}{|c|c|c|c|c|c|c|}
\hline & \multirow{2}{*}{ Kappa } & \multicolumn{3}{|c|}{ Asymptotic } & \multicolumn{2}{|c|}{$\begin{array}{c}\text { Asymptotic } 95 \% \\
\text { Confidence Interval }\end{array}$} \\
\hline & & Standard Error & z & Sig. & Lower Bound & $\begin{array}{l}\text { Upper } \\
\text { Bound }\end{array}$ \\
\hline $\begin{array}{l}\text { Overall } \\
\text { Agreement }\end{array}$ & -.145 & .052 & -2.773 & .006 & -.148 & -.141 \\
\hline
\end{tabular}

The reliability of the data collected through the use of the research instrument (questionnaire) is further enhanced by the result of the Kappa test (Table 8) often recommended when examining the reliability of Likert scale data. Fleiss's Kappa is used to estimate with a method of evaluation measured on a categorical scale, the degree of inter-raters' agreement of classification towards what one would expect if it were done at random (Glen, n.d). Its basic formula is as follows: 
Implications of Uncertainty Avoidance and Procrastination on Some West African EFL Learners' Academic Behaviors

$$
\mathrm{Kappa}(\mathbf{K})=\frac{P o-P e}{1-P e}\left\{\begin{array}{l}
P o \text { is the observed agreement } \\
P \text { e is the expected agreement }
\end{array}\right.
$$

Its coefficient varies most of the time between 0 (signifying an agreement due to chance, that is to say, identical to the random agreement) and 1 (signifying an ideal agreement). However, it is not excluded to have values less than or greater than 0 and 1 . Either this denotes the non-existence of chance or that the issue is a known problem that arises very often (Laerd Statistics, 2019, n.p). This explains the case observed in the present research where Fleiss's kappa is negative $(\mathrm{k})=-0.145$. It infers that the agreement is lower than the expected one by chance according to the identification of Fleiss (Fleiss, Levin, \&Paik, 2013) because of the asymptomatic value that is significantly different from zero ( $\mathrm{p}=$ .06). This suggests that the different closed-ended questions of the 24 items of the questionnaire are independent and prove that the respondents are from different geographical areas. It also implies that the respondents differ considerably in some major factors such as lifestyle, culture, age, marital status, education, socialization, liveliness, motivation, devotion, engagement, and upbringing.

P-value $(=0.000) \leq \alpha(=0.05)$ : there are statistically significant discrepancies between the means of independent (degree, program, gender, citizenship, marital status, and enrollment) and dependent (the 24 items) variables. It can be inferred that there are less than five chances in 100 that the outcomes are due to chance. The null hypothesis can therefore be dismissed.

\begin{tabular}{|c|c|c|c|c|c|c|}
\hline \multicolumn{7}{|c|}{ Table 9: ANOVA } \\
\hline & & Sum of & $\overline{\mathrm{df}}$ & Mean & $\overline{\mathrm{E}}$ & Sig \\
\hline \multicolumn{2}{|c|}{ Between People } & 714.283 & 211 & 3.385 & & \\
\hline \multirow{3}{*}{$\begin{array}{l}\text { Within } \\
\text { People }\end{array}$} & Betwe & 303.365 & 23 & \begin{tabular}{|l|}
13.19 \\
\end{tabular} & 12.317 & .000 \\
\hline & Residu & 5196.802 & 4853 & 1.071 & & \\
\hline & Total & 5500.167 & 4876 & 1.128 & & \\
\hline \multicolumn{2}{|l|}{ Total } & 6214.450 & 5087 & 1.222 & & \\
\hline \multicolumn{7}{|l|}{ Grand $M$} \\
\hline
\end{tabular}

The continuous and positively asymmetric value of Fisher's test $(F=12.317)$ as indicated in Table 9 further illustrates within a confidence interval of $95 \%$ the heterogeneity of the variances of the different variables rejecting by this way the hypothesis of nullity and then justifying the state of the validity of the research instrument and the results obtained. Since the null hypothesis is rejected, it is important to know which items elicit responses with significantly different means. This is indicated by the variance data presented in Table 10. The variation ratio tells us that the number of "agree" responses is 2.986 (approximately 3) times greater than the number of "neutral" given that the minimum mean of the responses given by the various participants to the closed-ended questions of the questionnaire is around 3,448 , therefore "neutral" and the maximum average of these responses is around 4,358, then "in agreement".

Table10. Summary Item Statistics

\begin{tabular}{|l|r|r|r|r|r|r|r|}
\hline & Mean & Minimum & Maximum & \multicolumn{1}{c|}{ Range } & \multicolumn{1}{c|}{$\begin{array}{c}\text { Maximum / } \\
\text { Minimum }\end{array}$} & \multicolumn{1}{c|}{ Variance } & N of Items \\
\hline Item Means & 4.039 & 3.448 & 4.358 & .910 & 1.264 & .062 & 24 \\
\hline Item Variances & 1.167 & .652 & 1.948 & 1.296 & 2.986 & .146 & 24 \\
\hline Inter-Item Covariances & .096 & -.457 & .808 & 1.265 & -1.770 & .042 & 24 \\
\hline Inter-Item Correlations & .084 & -.303 & .550 & .853 & -1.811 & .027 & 24 \\
\hline
\end{tabular}

The coefficient of the mean of the inter-item covariances is positive $(y=0.084)$. This suggests that the different responses given by respondents to each of the 24 items are linear and therefore evolve simultaneously according to their respective mean. Moreover, while the minimum coefficient of interitem covariances is negative $(\mathrm{y} 1=-0.457)$ and therefore decreasing, the maximum of inter-item covariances is positive $(y 2=0.808)$ then increasing. This indicates that the series of minimum "neutral" responses given by the respondents to the different items are independent while those of the maximum responses identified above as being that of "agree" are closed. The Interval of Variation (IV) or range of the variance distribution of the 24 items indicates a value of $x=1,296$ that is approximate to that of 
the range of covariances between items. This confirms that the answers given by the respondents are linear. Similarly, the value $(x=0.062)$ representing the variance of the means of the items being appreciably close to zero, shows that the means of the different responses elicited by the items are approaching and are around 4.039. This suggests that the majority of respondents indicated that they "agree" with each of the 24 items.

The average of the coefficient of inter-item correlations being positive and equal to 0.084 , this indicates the existence of a correlation between the answers given by the different respondents to the various questions contained in the items. Since the value $(x=0.27)$ of the variance of the inter-item correlations is positive and substantially equal to zero this suggests that the values of the inter-item correlations get closer and converge towards the mean (0.84) that is approximately equal to 1 . There would therefore be a perfect correlation between the majority of respondents' answers. Table 11 below better illustrates the different observations analyzed and interpreted above.

Table 11: Descriptive Statistics of the 24 items

\begin{tabular}{|c|c|c|c|c|c|c|c|}
\hline & $\mathrm{N}$ & & e Minimum & & Mean & $\begin{array}{c}\text { Std. } \\
\text { Deviation }\end{array}$ & Variance \\
\hline It is important to have instructions spelled out in detail so that I always know what I'm expected to do. & 227 & 4 & 4 & 1 & $5 \quad 4.07$ & 1.043 & 1.087 \\
\hline It is important to closely follow instructions and procedures. & 224 & 4 & 4 & 1 & $5 \quad 3.95$ & 1.159 & 1.342 \\
\hline Rules and regulations are important because they inform me of what is expected of me. & 224 & 4 & 4 & 1 & $5 \quad 4.25$ & .985 & .971 \\
\hline Standardized work procedures are helpful. & 225 & 4 & 4 & 1 & $5 \quad 4.20$ & .953 & .908 \\
\hline Instructions for operations are important & 224 & 4 & 4 & 1 & $5 \quad 4.37$ & .799 & .638 \\
\hline I often find excuses for not starting the work for this course & 224 & & 4 & 1 & $5 \quad 3.74$ & 1.233 & 1.520 \\
\hline I delay studying for this course. even when it is important & 224 & 4 & 4 & 1 & $5 \quad 3.63$ & 1.385 & 1.919 \\
\hline I postpone doing the work for this class until the last minute & 224 & & 4 & 1 & $5 \quad 3.43$ & 1.371 & 1.879 \\
\hline I promise my self I will do something for this course. and then put it off any way & 224 & 4 & 4 & 1 & $5 \quad 3.83$ & 1.205 & 1.451 \\
\hline I frequently put off getting started on the readings and assignments for this course & 223 & 4 & 4 & 1 & $5 \quad 3.57$ & 1.296 & 1.679 \\
\hline I study the lesson contents with other students & 224 & & 4 & 1 & $5 \quad 4.16$ & .928 & .862 \\
\hline I try to solve difficult problems with other students when I encounter them & 225 & 4 & 4 & 1 & $5 \quad 4.22$ & .928 & .861 \\
\hline I work with other students on projects or assignments & 225 & 4 & 4 & 1 & $5 \quad 4.16$ & .934 & .873 \\
\hline I ask other students for help when I can't understand a concept taught in my class & 225 & & 4 & 1 & $5 \quad 4.27$ & .825 & .681 \\
\hline I try to answer the questions that other students ask & 225 & & 4 & 1 & $5 \quad 4.18$ & .885 & .784 \\
\hline I feel a connection with the students who are in my classes & 225 & 4 & 4 & 1 & $5 \quad 4.22$ & .989 & .977 \\
\hline I feel a sense of belonging to the class community & 225 & 4 & 4 & 1 & $5 \quad 4.01$ & 1.094 & 1.196 \\
\hline I frequently interact with other students in my classes & 226 & 4 & 4 & 1 & $5 \quad 3.96$ & 1.179 & 1.390 \\
\hline Having fun in class. discussions. with the instructor or other students & 223 & 4 & 4 & 1 & $5 \quad 3.83$ & 1.277 & 1.631 \\
\hline Participating actively in small-group discussion forums & 223 & 4 & 4 & 1 & $\begin{array}{ll}5 & 4.27 \\
\end{array}$ & .799 & .639 \\
\hline Helping fellow students & 223 & 4 & 4 & 1 & $5 \quad 4.09$ & 1.076 & 1.158 \\
\hline Engaging in conversations & 223 & 4 & 4 & 1 & $\begin{array}{ll}5 & 4.12 \\
\end{array}$ & 1.052 & 1.107 \\
\hline Participating in the class discussion regularly & 221 & 4 & 4 & 1 & $5 \quad 4.24$ & 1.051 & 1.104 \\
\hline Getting to know other students in the class & 222 & & 4 & 1 & $5 \quad 4.22$ & 1.051 & 1.105 \\
\hline Valid N (listwise) & 212 & & & & & & \\
\hline
\end{tabular}

As explained earlier, the means of the answers provided by the different respondents to the various item's questions turn around the value of 4.00. This suggests most of them "agreed" with the statements measuring their beliefs towards the impact of uncertainty avoidance and procrastination on their engagement, feeling of belonging, collaboration, and participation. It implies that through the different 5-point Likert scale questions the respondents believed that the fear of the unknown makes them procrastinate on their English language learning as well as their personal growth in their learning environment. The following descriptive statistics tables and figures further illustrate the findings. 
Implications of Uncertainty Avoidance and Procrastination on Some West African EFL Learners' Academic Behaviors
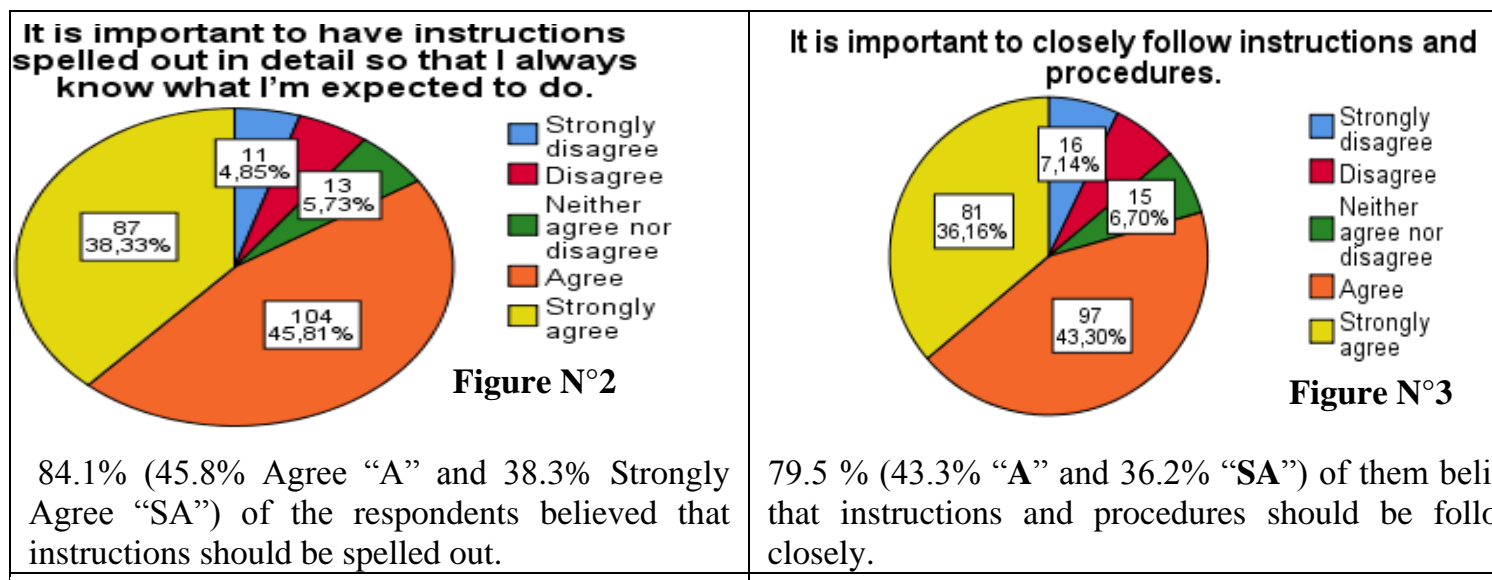

Figure $\mathbf{N}^{\circ} 3$

$79.5 \%$ (43.3\% "A" and 36.2\% "SA") of them believed that instructions and procedures should be followed closely.

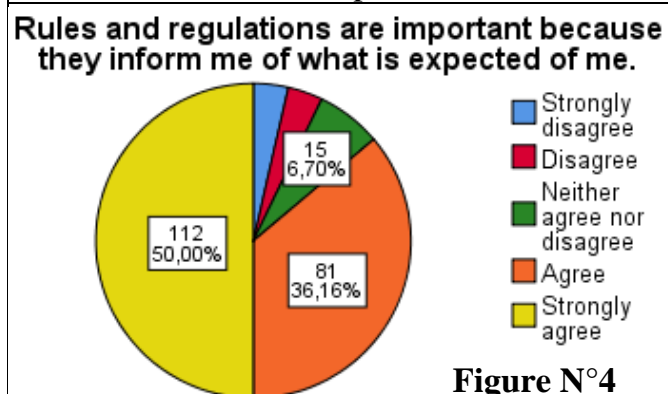

Figure $\mathbf{N}^{\circ} 4$

$86.2 \%$ (36.2\% "A" and 50.0 "SA") of them agreed that rules and regulations are important.
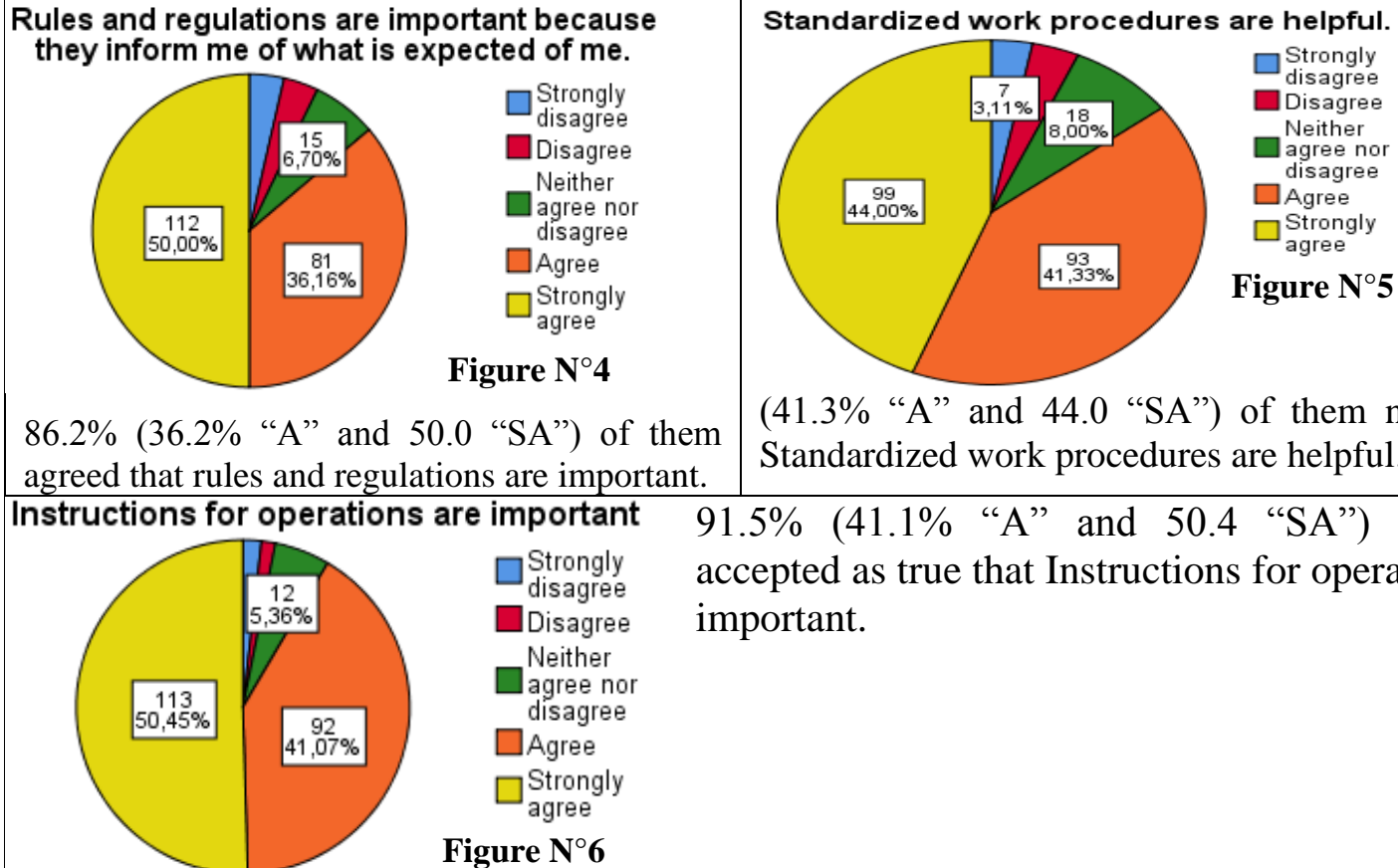

$85.3 \%$

(41.3\% "A" and 44.0 "SA") of them noted that Standardized work procedures are helpful.

91.5\% (41.1\% "A" and 50.4 "SA") of them accepted as true that Instructions for operations are important.

Inference 1: Based on the respondents' beliefs illustrated above, it can be suggested that learners $(85.32 \%)$ fear the uncertainty and prefer being informed in detail of events. This can cause a lack of self-confidence and motivation and develop anxiety among them. It can also affect considerably their academic performance. From the information provided by the five tables above, very few of the respondents $(14.68 \%)$ pretended to be not concerned about the issue of uncertainty. This may be due to a natural ability that they have to face any kind of new situation or to the action of their social environment, culture as well as home education (up bring).

Table12. Result of the analysis of the figures representing beliefs in uncertainty avoidance

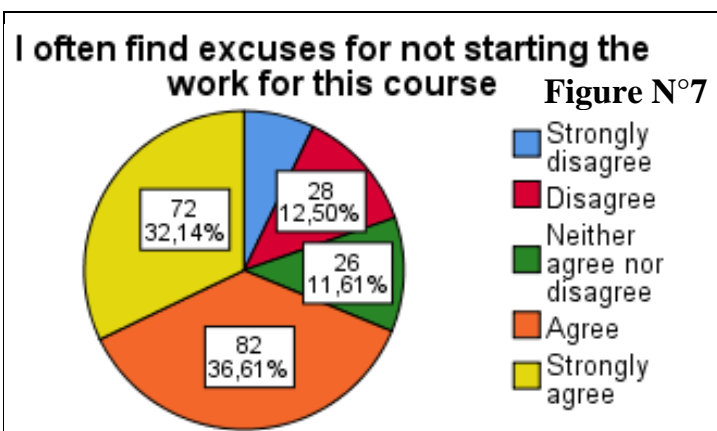

$68.7 \%(36.6 \%$ "A" and $32.1 \%$ "SA") of them confessed that they often find excuses for not starting a work.

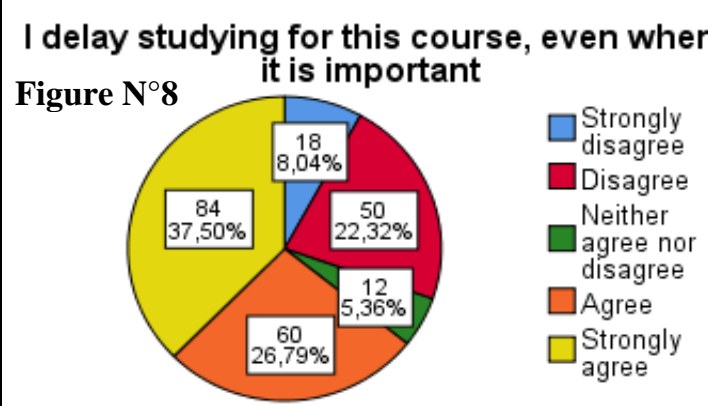

$64.3 \%$ (26.8\% "A" and 37.5\% "SA") of them admitted that they sometimes delay studying a course through this is crucial. 


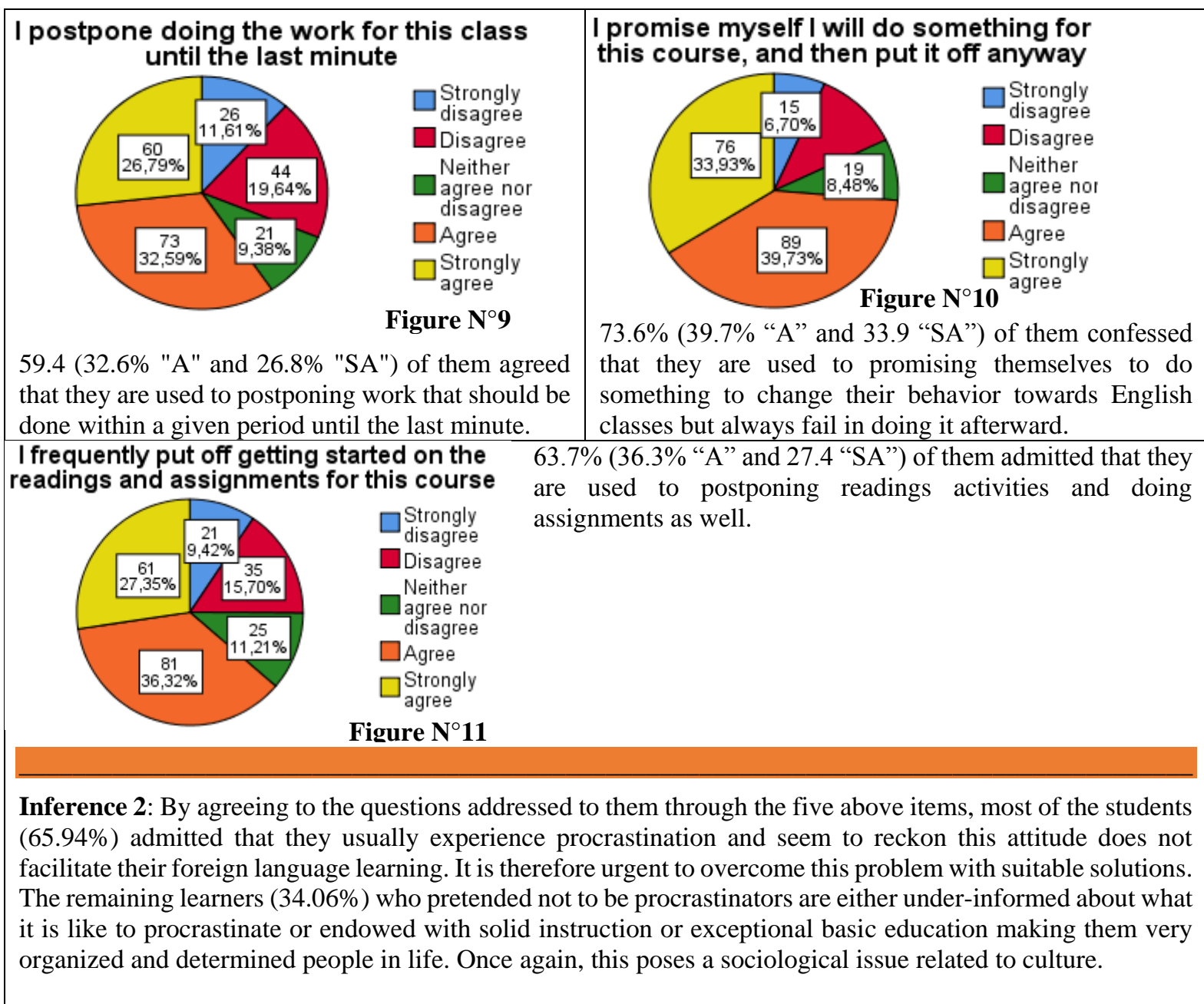

Table13. Result of the analysis of the figures representing beliefs in procrastination

\begin{tabular}{|c|c|c|c|c|c|c|}
\hline I study the lesson contents with other & $83.5 \%$ \\
students
\end{tabular}


Implications of Uncertainty Avoidance and Procrastination on Some West African EFL Learners' Academic Behaviors

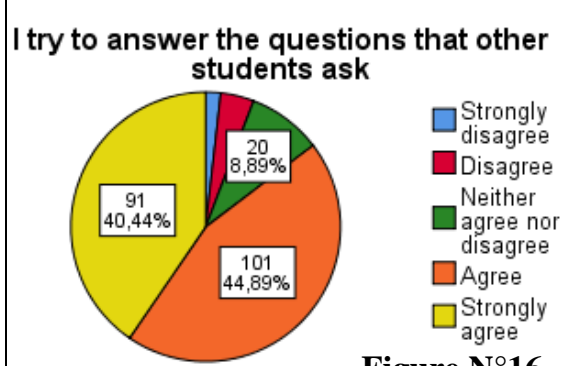

Figure $\mathrm{N}^{\circ} 16$

$85.3 \%(44.9 \%$ "A" and 40.4 "SA") of them admitted that they usually try to answer questions that their mates ask

Inference 3: The issue of learners' engagement with one another does not seem to arise too much for most of the learners who participated in the study. Many of them $(86.1 \%)$ think that they have a good collaborative relationship with their classmates. They think they are more outgoing when being with their mates to whom they nurture a spirit of mutual aid and brotherhood. Therefore, what may be at the root of the lack of dedication or commitment observed among other respondents (13.9\%)? This can be explained by the fact that the latter is not too sociable or have experienced emotional situations in the past. Internal or external work must be done on them to break with the spirit of individualism.

Table14. Result of the analysis of the figures representing beliefs in the sense of engagement

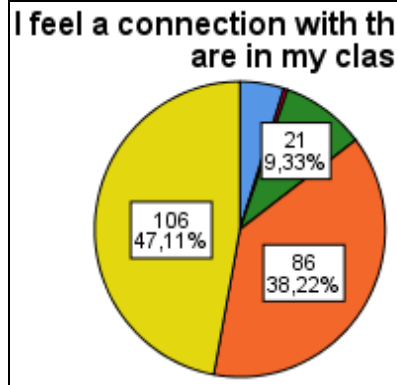

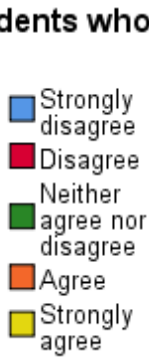

Figure $\mathbf{N}^{\circ} 17$

$85.3 \%$
$(38.2 \%$
"A"
and
47.1
"SA")
of
them

confessed they feel a classmates.

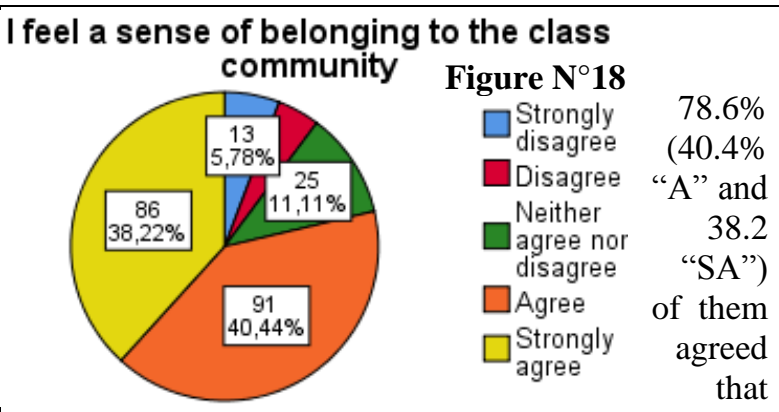

they feel a sense of belonging to the class community.

I frequently interact with other students in

$79.3 \%(41.2 \%$ "A" and 38.1 "SA") of them pretended my classes

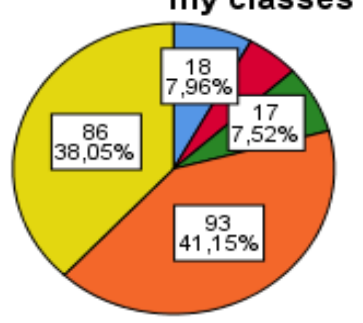

$\square$ Strongly

$\square$ Disagree

Neither

$\square$ agree nor

disagree

$\square$ Agree

$\square$ Strongly

Figure $\mathrm{N}^{\circ} 19$

Inference 4: Most of the respondents $(81.06 \%)$ believed that they do not have any problem to interact with their classmates. However, an important question remains. Apart from the rest of them (18.93\%) who think they have problems interacting with their classmates or developing a certain connection with them, how can we explain the fact that most of these students who believe they are extroverts are also procrastinators? This suggests that procrastination does not always depend on shyness but above all, on the pressure that one puts on oneself personally.

Table15. Result of the analysis of figures representing beliefs in the sense of interaction

\begin{tabular}{|l|l|l|} 
Having fun in class, discussions, with the \\
instructor or other students
\end{tabular}




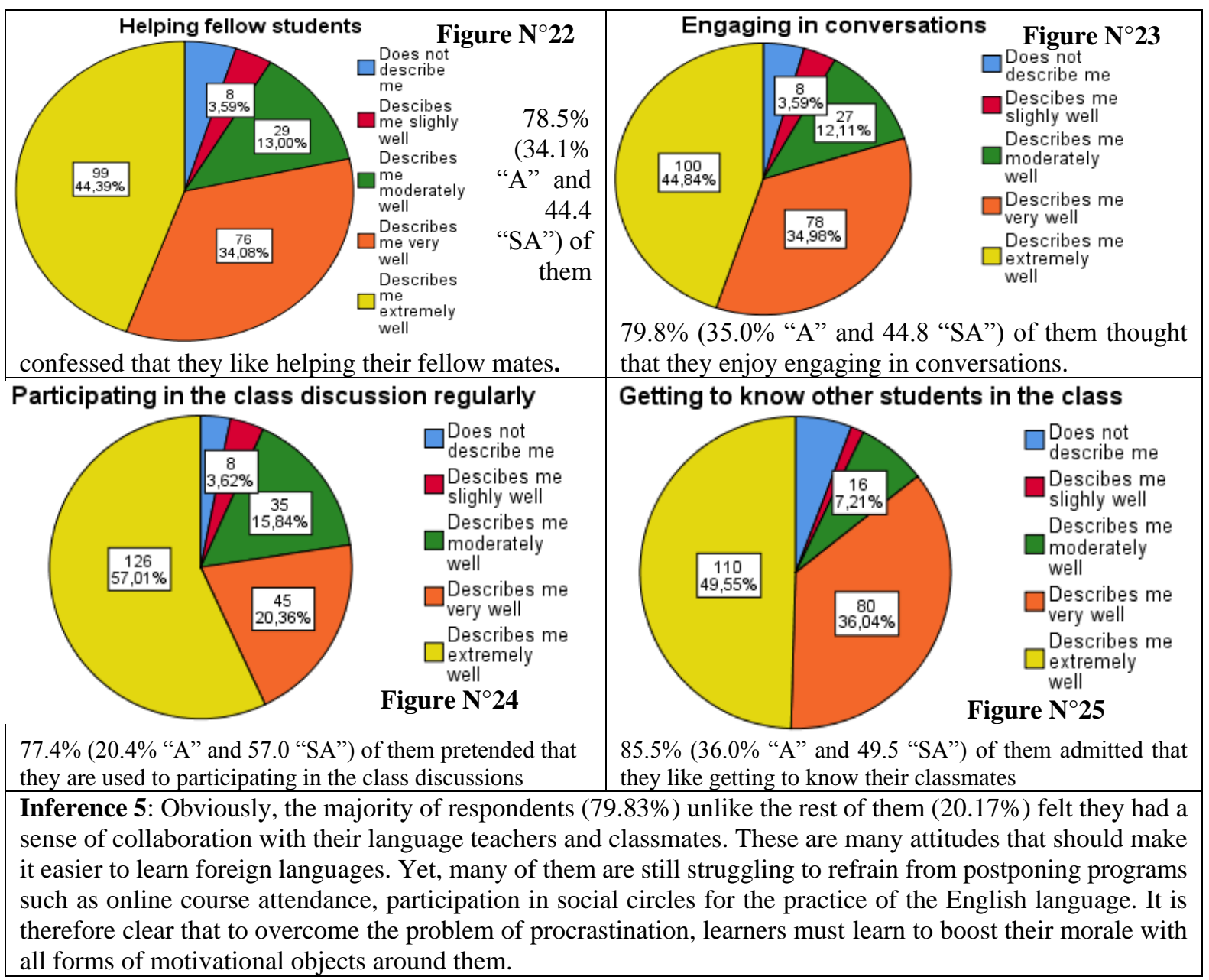

Table16. Result of the analysis of figures representing beliefs in the sense of collaboration

\section{Justification:}

From the content of the five inferences presented above, it follows that the issue of uncertainty avoidance and procrastination arises tremendously among learners and has a significant impact on their linguistic and academic performance. There is reason to believe this somewhat hinders inter-learner and learner-teacher relations.

On the other hand, in terms of whether this issue varies by gender, it was found that males and females had approximately the same rate of avoidance of uncertainty and procrastination. This is best illustrated through tables 17 and 18 and graphs (Cf. Table19) below. Indeed, the directional and symmetric measures indicate the estimated level of significance of the answers provided by males and females to the item's questions, measuring the avoidance of uncertainty and procrastination equal to 0.00 . As this is below 0.05 , we can assume that there is a statistically relevant association between the responses given by males and females. Yet, the value of each measure is below 0.150 (Cf. Table 17), so while the correlation is different from 0 it is still quite slight. Similarly, the total "coefficient of significance" of Pearson's R (interval by interval) and the one of Spearman Correlation (ordinal by ordinal) for male and female respondents is approximately $0.01 \leq 0.05$ (Cf. Table 18). This shows that the beliefs of these respondents towards those four items are homogeneous. In other words, of the 159 males $(70.4 \%)$ and 67 females (29.6\%) out of the 208 who disclosed their gender over the 230 respondents, around 72 men(49.66\%) and females $26(45.62 \%)$ from Nigerien students, 71 (48.9\%) males and $29(50.88 \%)$ females from Beninese students, and 2 males (1.38\%), as well as 2 females (1.40\%) from international students, agreed (strongly agreed) with the items measuring the uncertainty avoidance and procrastination. This means the respondents in general, express a high level of uncertainty and tend to procrastinate as regards the completion of their academic activities. 


\section{DISCUSSION}

Procrastination, this unhealthy tendency to put off until tomorrow what we can do today, always starts with the desire or the will to accomplish something that we know is beneficial to us. In a repetitive process, you manage to plan your program well and that is precisely where the trap lies. This intention that we have to do things well comes up against unforeseen circumstances or a lack of motivation.

The disrespect or the lack of personal pressure on oneself leads the learner to fall into the trap. In no time, he/she sees him/herself pushing back the date on which he/she plans to accomplish his/her task, and as the saying often goes, "who postpones until tomorrow finds misfortune along the way".

By dint of telling themselves that they still have time to do their homework or devote themselves to learning their target language, EFL learners suddenly realize they no longer have enough time to accomplish their tasks. Or quite simply, he/she finds later on that he/she is no longer motivated by the same determination as before. The bravest will still try to put in the task but in vain. In trying to cheer themselves up with the adage "better late than never", they will soon find themselves faced with another challenge; that of the 'false start' that they will try in vain to remedy because they have stopped having the same enthusiasm that they had when they were nourishing themselves with the achievement of this project.

Having thus not been able to achieve the desired objective, the learner enters the phase of panic or total discouragement that can seriously affect him/her regarding his/her health and his/her projects that he/she has many chances of never carrying out again.

When faced with the decision to take online courses, the learner or future learners of the English language, with all the motivation one can have, must arm themselves with a lot of courage and selfsacrifice. If necessary, they must learn to plan to be exacting towards themselves in respecting scrupulously their learning program. In addition to the fear of the unknown, the learner is often afraid of making mistakes or not being able to get to be up to the task. Moreover, ignorance of the use of computer tools and the Internet can also be a cause of procrastination among learners. With the advent of the generalized COVID-19 pandemic, most institutions around the world have opted for seminars, training, or online courses through the use of computer and audiovisual pieces of equipment.

The student who has always hidden him/herself behind his/her shyness will not stop postponing to the future the date he/she will start taking online classes. Even though he/she should end up by deciding to participate in them, he/she will prefer hiding behind the camera and the microphone of his/her computer by only making use of the hearing organ (the ear) that he/she will struggle to discipline, considering all the forms of distractions to which he/she may be subject. Self-regulation seems to be his best approach if he/she dreams to achieve his goals one day. Therefore, he/she has to do self-examination and accept him/herself as he/she is and to be mentored by his language instructor or, failing that, by anyone with this profile.

In this study, the majority of respondents admitted to having experienced procrastination. Based on the results obtained, it turned out that this phenomenon does not make a difference between men and women even if at first sight we tend to switch to the side of women as being the beings who would be the most prone to procrastination. But that is another debate. Surprisingly enough, we have seen that this phenomenon is the prerogative of culture and initial or basic education. Beninese learners who participated in this study tended to be more prone to procrastination than those recruited in Niger. This can undoubtedly be explained by the fact that the majority of these respondents recruited in Niger were learners enrolled in masters and doctorate courses unlike those recruited in Benin who were only enrolled in bachelor's degree training. The human and intellectual maturity that Nigerien respondents have over Beninese respondents seems to have impacted their opinions on the level of uncertainty avoidance and procrastination towards them. However, this phenomenon could be regulated thanks to the observance of some sociological and cultural rules such as the principles of self-help, the management of anxiety, the development of self-taught notions, knowledge of the culture of the target language, socialization, mastery of objects or tools with which we are often surrounded within the society such as those that are related to technology.

\section{Suggestions, Recommendations, and Conclusion}

The present study has investigated the factors known as being those that impede EFL learners to take online classes. It has highlighted the causes of uncertainty avoidance and procrastination among foreign 
language learners. Among the many causes of this phenomenon are the lack of self-confidence, maturity, socialization, motivation, devotion, sense of engagement, education, and upbringing. In addition to all that, it is worth mentioning that some learners have natural predispositions against procrastination. Moreover, elements like the lifestyle, culture, and personal development strategies help to stay away from this syndrome.

The different outcomes of this research work have also shown that males and females do not differ in terms of their level of uncertainty avoidance and procrastination. However, it is noteworthy specifying that this finding may be based on the difference of background knowledge, age group, and maturity of the subjects involved in the investigation. It would then be appropriate for future studies to be carried out on the same research question in different contexts to further examine the level of avoidance of uncertainty and procrastination in men and women. However, it can be recommended that to help the EFL learner cope with procrastination problems, the following principles should be applied. There are (1) Anxiety management, (2) Self-taught notion development, (3) Audiovisual materials knowledge development, (4) Self-regulation learning, (5) Motivation factors enhancement, (6) Learner-learner and teacher-learner interaction development implementation, (7) Socialization, and (8) Life rule adoption.

\section{REFERENCES}

[1] Allen, I. E. \& Seaman, J. (2017). Digital learning compass: Distance education enrollment report. Boston, MA: Babson Survey Research Group.

[2] Asikhia, O. A. (2010). Academic Procrastination in Mathematics: Causes, Dangers, and Implications of Counselling for Effective Learning. International education studies, 3(3), 205-210.

[3] Beck, B. L., Koons, S. R., and Milgrim, D. L. (2000). Correlates and consequences of behavioral procrastination: The effects of academic procrastination, self-consciousness, self-esteem, and selfhandicapping. Journal of social behavior and personality, 15(5), 3.

[4] Beswick, G., Rothblum, E. D., and Mann, L. (1988). Psychological antecedents of student procrastination. Australian psychologist, 23(2), 207-217.

[5] Burch, G. F.; Heller, N. A.; Burch, J. J.; Freed, R.; Steed, S. A. (2015). Student engagement: Developing a conceptual framework and survey instrument. Journal of Education for Business, 9, 224-229.

[6] Burns, S.N, and Grove, S.K. (2003). Understanding nursing research (3rd edition). Philadelphia: Saunders.

[7] Bud, M. (2014). ). Five phases of procrastination. Retrieved, Friday, September 25, 2020, from https:// thetab.com/uk/manchester/2014/03/27/the-5-stages-of-procrastination-4548

[8] Cho, M. H.; Cho, Y. (2014). Instructor scaffolding for interaction and students' academic engagement in learning: Mediating role of perceived class goal structures. Int. High. Educ., 21, 25-30.

[9] Corkin, D. M., Yu, S. L., Wolters, C. A., and Wiesner, M. (2014). The role of the college classroom climate on academic procrastination. Learn. Individ. Dif. 32, 294-303. doi: 10.1016/j.lindif.2014.04.001

[10] Dixson, M. D. (2015). Measuring student engagement in the course: The student engagement scale (OSE). Learning, 19, 51-65.

[11] Dixson, M. D. (2015). Measuring student engagement in the online course: The Online Student Engagement Scale (OSE). Online Learning, 19(4), n4

[12] Fleiss, J. L., Levin, B., \& Paik, M. C. (2013). Statistical methods for rates and proportions. john wiley \& sons.

[13] Gargari, R. B., Sabouri, H., and Norzad, F. (2011). Academic procrastination: The relationship between causal attribution styles and behavioral postponement. Iranian journal of psychiatry and behavioral sciences, 5(2), 76.

[14] Glen, S. (n.d). "Fleiss' Kappa" From StatisticsHowTo.com: Elementary Statistics for the rest of us! Retrieved October 07, 2020, from https://www.statisticshowto.com/fleiss-kappa/

[15] Grunschel, C., Patrzek, J., Klingsieck, K. B., and Fries, S. (2018). I'll stop procrastinating now!” Fostering specific processes of self-regulated learning to reduce academic procrastination. J. Prev. Interv. Community 46, 143-157. doi: 10.1080/10852352.2016.1198166

[16] Hofstede, G. (1980). Culture's consequences: International differences in work-related values. Beverly Hills, CA: Sage.

[17] Hofstede, G. (2001). Culture's consequences: Comparing values, behaviors, institutions, and organizations across nations, $\left(2^{\text {nd }}\right.$ ed). Thousand Oaks, CA: Sage Publications.

[18] Kirkman, B. L., Lowe, K. B., and Gibson, C. B. (2001). Twenty Years of" Culture's Consequences": A Review of the Empirical Research on Hofstede's Cultural Value Dimensions. The University of Southern California, Center for Effective Organizations, Marshall School of Business. 
Implications of Uncertainty Avoidance and Procrastination on Some West African EFL Learners' Academic Behaviors

[19] Kozulin, A. (1990). Vygotsky's psychology: A biography of ideas. Cambridge, MA: Harvard University Press

[20] Lantolf, J. P. (Ed.). (2000). Sociocultural theory and second language learning (Vol. 78, No. 4). Oxford: Oxford University Press.

[21] Laerd Statistics (2019). Fleiss' kappa using SPSS Statistics. Statistical tutorials and software guides. Retrieved October 07, 2020, from https://statistics.laerd.com/spss-tuorials/fleiss-kappa-in- $\quad$ spssstatistics. php

[22] Lee, J., Song, H., \& Hong, A. (2019). Exploring factors, and indicators for measuring students' sustainable engagement in e-learning. Sustainability, 11, 985; doi:10.3390/su11040985

[23] Lieberman, C. (2019). Why you procrastinate (it has nothing to do with self-control). The New York Times. Retrieved from: https://www. nytimes. com/2019/03/25/smarter-living/why-you- procrastinate-it-hasnothing-to-do-with-self-control. html.

[24] Medan, J. (2017). Five phases of procrastination. Retrieved, Friday, September 25, 2020, from https:// www .hercampus.com/school/chapman/5-stages-procrastination

[25] Murray, J. (2018). Student-led action for sustainability in higher education: A literature review. Int. J. Sustain. High. Educ, 19, 1095-1110.

[26] Nordby, K., Klingsieck, K., and Svartdal, F. (2017). Do procrastination-friendly environments make students delay unnecessarily? Soc. Psychol. Educ. 20,491-512. doi: 10.1007/s11218-017- 9386-X

[27] NSSE (2017). Engagement insights. Survey findings on the quality of undergraduate education. National Survey of Student Engagement, Indiana University Center for Postsecondary Research and Planning: Bloomington, IN, USA.

[28] Popoola, B. I. (2005). A study of the relationship between procrastinatory behavior and academic performance of undergraduate students in a Nigerian University. African Symposium: An Online Journal of Educational Research Network. In the African Symposium: An Online Journal of African Educational Research (p. 60).

[29] Risk, G. (2017). Five phases of procrastination. [Retrieved, Friday, September 25, 2020, from https://northcoastcourier.co.za/83349/five-phases-procrastination/

[30] Rothblum, E. D., Solomon, L. J., and Murakami, J. (1986). Affective, cognitive, and behavioral differences between high and low procrastinators. Journal of counseling psychology, 33(4), 387.

[31] Senecal, C., Koestner, R., and Vallerand, R. J. (1995). Self-regulation and academic procrastination. The journal of social psychology, 135(5), 607-619.

[32] Sirois, F. M., and Pychyl, T. A. (Eds.). (2016). Procrastination, health, and well-being. San Diego: Academic Press.

[33] Solomon, L. J., \& Rothblum, E. D. (1984). Academic procrastination: Frequency and cognitive-behavioral correlates. Journal of counseling psychology, 31(4), 503.

[34] Speidel, G., \& Nelson, K. (1989). A fresh look at imitation in language learning. InG. Speidel \& K. Nelson (Eds.), the many faces of imitation in language learning (pp. 1-22). New York: Springer Verlag.

[35] Steel, P. (2007). The nature of procrastination: a meta-analytic and theoretical review of quintessential selfregulatory failure. Psychological Bulletin, 133, 65-94.doi: 10.1037/0033-2909.133.1.6

[36] Swan, K., Shea, P., Fredericksen, E., Pickett, A., Pelz, W., and Maher, G. (2000). Building knowledgebuilding communities: Consistency, contact, and communication in the virtual classroom. Journal of Educational Computing Research, 23(4), 359-383.

[37] Tice, D. M., and Baumeister, R. F. (1997). Longitudinal study of procrastination, performance, stress, and health: The costs and benefits of dawdling. Psychological science, 8(6), 454-458.

[38] Tuckman, B. W., Abry, D. A., Smith, D. R., \& Arby, D. (2008). Learning and motivation strategies: Your guide to success. The Ohio State University: Pearson/Prentice Hall.

[39] Visser, L., Korthagen, F. A., and Schoonenboom, J. (2018). Differences in learning characteristics between students with high, average, and low levels of academic procrastination: students' views on factors influencing their learning. Frontiers in psychology, 9, 808.

[40] Vonderwell, S.,and Zachariah, S. (2005). Factors that influence participation in learning Journal of

[41] Research on Technology in Education, 32(2), 213-230.

[42] Wang, L. (2007). Sociocultural learning theories and information literacy teaching activities in higher education. Reference \& User Services Quarterly, 149-158.

[43] Winegar, L. (1997). Can internalization be more than a magical phrase? Notes toward the constructive negotiation of this process. In C. Lightfoot \& B. Cox (Eds.), Sociogeneticperspectives on internalization. Mahwah, NJ: Lawrence Erlbaum Associates.

[44] Zimmerman, B. J. (2002). Becoming a self-regulated learner: An overview. Theory into Practice, 41(2), 64-70. 
[45] Zimmerman, B. J., \& Schunk, D. H. (2011). "Self-regulated learning and performance," in B. J. Zimmerman and D.H. Schunk (Eds.). Handbook of self-regulation of learning and performance (pp. 1-12). New York, NY: Routledge.

\section{AUTHOR'S BIOGRAPHY}

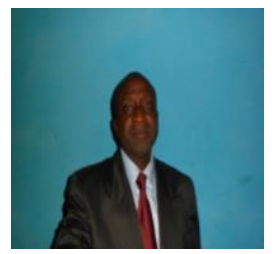

Moussa Tankari is an Assistant Professor of English at the University of Zinder's English Department in Niger. He received his EdD in Curriculum and Instruction with a focus on Educational Technology from Northern Arizona University, AZ (USA) and his Master's degree in TESL/TEFL from Saint Michael's College in Colchester, VT (USA). Tankari's research interests include teacher development and cognition, online learning, innovative pedagogy in higher education, cultural orientations, active learning, and student satisfaction. His recent and current works focus on the use of Information and Communication Technology to enhance teaching and learning in higher education, the implications of uncertainty avoidance and procrastination on student academic behaviors, and student and instructor readiness for the integration of technology in teaching and learning in low-tech environments.

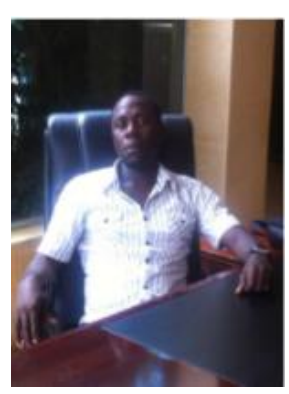

Coffi Martinien Zounhin Toboula is an Assistant Professor at the Department of Literature, Languages, Arts and Communication (FLLAC) of the University of Abomey-Calavi (UAC). Holder of a Ph.D. in Linguistics and Didactics of the English language, his areas of interest are psycho-pedagogy, learner psychology, anxiety management, promotion of oral communication, leadership, and extracurricular activities, and innovation of teaching and research techniques in TEFL. Competent communicator and member of Toastmasters International, he is a promoter and charter member of several English language learning circles including the Universal Toastmasters Club of Cotonou. Freelance translator and interpreter, he is also in charge of the management of a language laboratory and passionate about writing and research in human psychology.

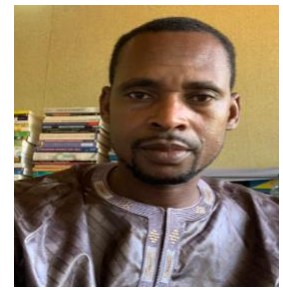

Hamissou Ousseini is an Assistant Professor of Language Education (English) and Applied Linguistics at Université Abdou Moumouni (Niger). He holds a Ph.D. from the University of East Anglia (UK) where he conducted research on initial EFL teacher education and professional development. He also holds a Master's degree in TESOL from Indiana University of Pennsylvania (USA). Hamissou's research interests include teacher cognition, lesson study/action research, translanguaging, and issues relevant to ELT methodology. He currently teaches courses on TEFL, Second Language Acquisition, and Research Methodology.

\section{Appendix}

\section{Survey questionnaire}

PART l: Demographic information

1. What is the name of your degree program?

2. What degree are you seeking from your institution?

A. Bachelor's

B. Master's

C. Doctorate

3. What is your gender?

A. Male

B. Female

C. Other (please, specify)

D. Prefer not to disclore

4. What is your country of citizenahip?

5. Please, select your marital status.

A. Married

B. Widowed

C. Divorcee

D. Separated

E. Single (never got married)

F. Prefer not to disclone

6. Ase you currently enrolled as a full-time student?

A. Yes

B. Nov 
Implications of Uncertainty Avoidance and Procrastination on Some West African EFL Learners' Academic Behaviors

PART 2: Within your current course(s), how much do you agree or disagree with the following statements, behaviors, thoughts, and or feelings?

Please select one answer for each statement.

Please, use the following response to rate each of the sub-scales below:

$1=$ Completely disagree; $\mathbf{2}=$ Disagree; $3=$ Neutral $\mathbf{4}=$ Agree; $\mathbf{5}=$ Completely agree

\begin{tabular}{|c|c|c|c|c|c|c|}
\hline $\mathrm{N}^{\circ}$ & & 1 & 2 & 3 & 4 & 5 \\
\hline Ul & It is important to have instructions spelled out in detail so that I always lonow what I'm expected to do. & & & & & \\
\hline $\mathrm{U} 2$ & It is important to closely follow inutructions and procedures. & & & & & \\
\hline U3 & Rules and regulations are important because they inform me of what is expected of me. & & & & & \\
\hline U4 & Standardized work procedures are helpful. & & & & & \\
\hline U5 & Instructions for operations are important & & & & & \\
\hline PRO1 & I often find excuses for not starting the work for this course. & & & & & \\
\hline PRO2 & I delay studying for this course, even when it is important. & & & & & \\
\hline PRO3 & I postpone doing the work for this class until the last minute. & & & & & \\
\hline PRO4 & I promise myself I will do something for this course, and then put it off anyway. & & & & & \\
\hline PRO5 & I frequently put off getting started on the readings and assignments for this course. & & & & & \\
\hline PCOLl & I study the lesson contents with other students. & & & & & \\
\hline PCOL2 & I try to solve difficult problems with other students when I encounter them. & & & & & \\
\hline PCOL3 & I work with other students on projects or assignments. & & & & & \\
\hline PCOL4 & I ask other students for belp when I can't understand a concept taught in my class. & & & & & \\
\hline PCOL5 & I try to answer the questions that other students ask. & & & & & \\
\hline CS1 & I feel a connection with the students who are in my classes. & & & & & \\
\hline $\operatorname{cs} 2$ & I feel a sense of belonging to the class community. & & & & & \\
\hline $\operatorname{cs} 3$ & I frequently interact with other students in my classes & & & & & \\
\hline
\end{tabular}

PART 3: INSTRUCTIONS: Within your current course, how well do the following behaviors, thoughts, and feelings describe you? Please select one answer for each statement.

$1=$ not at all characteristic of me; 2 = not characteristic of me; $3=$ neutral; $4=$ characteristic of me; $5=$ very characteristic of me

\begin{tabular}{|c|c|c|c|c|c|c|}
\hline $\mathrm{N}^{\circ}$ & & 1 & 2 & 3 & 4 & 5 \\
\hline P1 & Having fun in class, discussions, with the instructor or other students & & & & & \\
\hline P2 & Participating actively in imall-group discussion forums & & & & & \\
\hline P3 & Helping fellow students & & & & & \\
\hline P4 & Engaging in conversations & & & & & \\
\hline P5 & Participating in the class discussion regularly & & & & & \\
\hline P6 & Getting to know other students in the class & & & & & \\
\hline
\end{tabular}

Thank you very much for your time and effort!

Citation: Moussa Tankari, et.al. "Implications of Uncertainty Avoidance and Procrastination on Some West African EFL Learners' Academic Behaviors" International Journal on Studies in English Language and Literature (IJSELL), vol 8, no. 11, 2020, pp. 1-19. doi: https://doi.org/10.20431/2347-3134.0811001.

Copyright: (C) 2020 Authors. This is an open-access article distributed under the terms of the Creative Commons Attribution License, which permits unrestricted use, distribution, and reproduction in any medium, provided the original author and source are credited. 